\title{
Time Courses of Central Frequencies of Low Frequency Components of Systolic and Diastolic Pressures and RR Intervals Variabilities in Response to Incremental Isometric Exercise
}

\author{
Alejandra Guillén-Mandujano, Salvador Carrasco-Sosa \\ Universidad Autónoma Metropolitana-I, CDMX, México
}

\begin{abstract}
To test the sympathetic activity estimating capability of central frequencies of low frequency $\left(_{C F} L F\right)$ components of systolic pressure $\left({ }_{C F} L F_{S P}\right)$, diastolic pressure $\left({ }_{C F} L F_{D P}\right)$ and $R-R$ intervals $\left({ }_{C F} L F_{R R}\right)$, in 31 healthy subjects performing continuously increasing legs muscle force until fatigue, we assessed: the instantaneous time courses of ${ }_{C F} L F_{S P}, C F L F_{D P}, C_{F} L F_{R R}$, their respective low frequency powers $\left({ }_{P} L F\right)$, estimated by a time-frequency distribution, ${ }_{C F} L F-P L F$ correlations and the comparisons between ${ }_{C F} L F$. Based on the threshold effect they showed, the time courses of all measures were divided into before (BTP) and after (ATP) threshold periods. Time courses of ${ }_{C F} L F_{S P},{ }_{C F} L F_{D P}$ and ${ }_{C F} L F_{R R}$ showed: 1. similar patterned responses of gradual increment in BTP, abrupt decrease in ATP and fast increment in the initial recovery period $(I R P)$, inverse to the pattern presented by ${ }_{P} L F$ dynamics; 2. 20-s epoch means $(E M)$ differences $(p<0.04)$ between them in control and BTP according to the inequality ${ }_{C F} L F_{R R}>_{C F} L F_{S P}>_{C F} L F_{D P}$, that disappeared in ATP and IRP. ${ }_{C F} L F-P L F$ correlations $(p<0.01)$ of the three variables were negative and greater $(p<0.01)$ in ATP than BTP and IRP. Our findings support that ${ }_{C F} L F$ can be used as sympathetic activity measures with some specificity: ${ }_{C F} L F_{R R}$ for the cardiac sympathetic outflow and ${ }_{C F} L F_{D P}$ for the vasomotor one.
\end{abstract}

\section{Introduction}

In the corpus of basic knowledge on HRV established by consensus, only the powers of the low $(\mathrm{p} L F)$ and high frequency components were considered reliable autonomic activity indexes [1]. $\mathrm{p} L F$ of cardiovascular variability (CVV) spectra have been successfully used as noninvasive estimators of sympathetic activity, the one corresponding to systolic pressure $\left({ }_{\mathrm{P}} L F_{\mathrm{SP}}\right)$ showing better consistency than that of R-R intervals series $\left({ }_{\mathrm{P}} L F_{\mathrm{RR}}\right)$ [2].

In a previous study we reported, under conditions of continuously increasing muscle force (CIMF) by performing handgrip and one leg extension, the significant correlation between the time courses of ${ }_{\mathrm{P}} \mathrm{LF}_{\mathrm{SP}}$, ${ }_{\mathrm{P}} \mathrm{LF}$ of diastolic pressure $\left(\mathrm{p}_{\mathrm{P}} \mathrm{F}_{\mathrm{DP}}\right)$ and ${ }_{\mathrm{P}} \mathrm{LF}_{\mathrm{RR}}$, as well as their similar detection of the onset of the abrupt increase of sympathetic activity, triggered by the activation of metaboreflex, threshold effect that allows dividing the sympathetic response into before threshold period (BTP) and after threshold period (ATP) [3].

Few reports have documented that maneuvers that increase sympathetic activity, such as the active orthostatic test [4] and dynamic exercise [5], provoke a leftward shift of the central frequency of ${ }_{\mathrm{P}} \mathrm{FF}_{\mathrm{RR}}\left(\mathrm{CF}_{\mathrm{CF}} \mathrm{LF}_{\mathrm{RR}}\right)$. However, the effects of sympathoexcitatory conditions on either the central frequencies of ${ }_{\mathrm{P}} \mathrm{F}_{\mathrm{SP}}\left(\mathrm{CF}_{\mathrm{CF}} \mathrm{LF}_{\mathrm{SP}}\right)$ and of ${ }_{\mathrm{P}} \mathrm{LF}_{\mathrm{DP}}\left({ }_{\mathrm{CF}} \mathrm{LF}_{\mathrm{DP}}\right)$, or on the relation between ${ }_{\mathrm{P}} \mathrm{LF}$ and their central frequencies $\left({ }_{\mathrm{CF}} \mathrm{LF}\right)$, have not been reported. Moreover, it is still unknown whether the baseline values of ${ }_{\mathrm{CF}} \mathrm{LF}_{\mathrm{SP}}, \mathrm{CF}_{\mathrm{CF}} \mathrm{LF}_{\mathrm{DP}}$ and $\mathrm{CF}_{\mathrm{CF}} \mathrm{LF}_{\mathrm{RR}}$ are similar or not.

To provide evidence of the ${ }_{\mathrm{CF}} \mathrm{LF}$ capability to estimate the sympathetic outflow arriving at the heart or the vessels, we assessed, in healthy subjects performing twolegs CIMF, the differences between the instantaneous time courses of ${ }_{\mathrm{CF}} \mathrm{LF}_{\mathrm{SP}}, \mathrm{CF}_{\mathrm{CF}} \mathrm{LF}_{\mathrm{DP}}$ and ${ }_{\mathrm{CF}} \mathrm{LF}_{\mathrm{RR}}$, as well as their relationship with ${ }_{\mathrm{P}} \mathrm{LF}_{\mathrm{SP}}, \mathrm{P}_{\mathrm{P}} \mathrm{F}_{\mathrm{DP}}$ and ${ }_{\mathrm{P}} \mathrm{LF}_{\mathrm{RR}}$, computed by a time-frequency distribution.

\section{Methods}

\subsection{Subjects}

Thirty one healthy, nonsmoking and sedentary subjects, 24 men and 7 women, participated. Their age, height and weight were $22.1 \pm 2.7$ years, $167.6 \pm 7.9 \mathrm{~cm}$ and $66.8 \pm 11.3 \mathrm{~kg}$ respectively. Their written informed consent was requested to participate. This study was approved by the ethics committee of our university.

\subsection{Protocol}

In a first visit to the laboratory, the health status of the subjects was evaluated and they were trained to correctly execute the isometric exercise. In a second visit, the 
experimental procedure was carried on. Each session consisted on three successive stages: 1 min of control; subject performing CIMF in sitting position, following a target linear pattern visually presented, by isometrically extending both legs at a rate of $0.2 \mathrm{~kg} . \mathrm{s}^{-1}$ until exhaustion, where the maximal force was attained; and recovery for 2 min. ECG, arterial pressure (AP) and muscle force (MF) were recorded throughout the entire session.

\subsection{Signal recording and acquisition}

ECG was detected at the thoracic bipolar lead CM5 using a bioelectric amplifier (Biopac Systems). AP was recorded by Finapres (Ohmeda). MF was measured with a dynamometer (Stoelting) mechanically adapted to a chair. All signals were digitized at a sampling rate of $1 \mathrm{kHz}$ via an acquisition and display system (Biopac Systems).

\subsection{Data processing}

Fiducial points of ECG and AP recordings were detected to construct the RR, systolic pressure (SP) and diastolic pressure (DP) time series, which were cubicspline interpolated, resampled at $4 \mathrm{~Hz}$ and detrended. Time-frequency spectra of the series were estimated with the smoothed pseudo-Wigner-Ville distribution and integrated in the standard low-frequency band of HRV spectral analysis to compute the instantaneous time courses of ${ }_{\mathrm{P}} \mathrm{LF}_{\mathrm{SP}},{ }_{\mathrm{P}} \mathrm{LF}_{\mathrm{DP}},{ }_{\mathrm{P}} \mathrm{LF}_{\mathrm{RR}}, \mathrm{CF}_{\mathrm{CF}} \mathrm{LF}_{\mathrm{SP}}, \mathrm{CF}_{\mathrm{CF}} \mathrm{LF}_{\mathrm{DP}}$ and ${ }_{\mathrm{CF}} \mathrm{LF}_{\mathrm{RR}}$.

MF was expressed as percentage of the individual maximal force $\left(\% \mathrm{MF}_{\mathrm{MAX}}\right)$. During CIMF, the threshold effect was visualized as an inflection point in both ${ }_{\mathrm{CF}} \mathrm{LF}$ and ${ }_{\mathrm{P}} \mathrm{LF}$ dynamics, and detected, subject by subject, using the $\mathrm{V}$-slope method to divide the measures response into BTP and ATP. Indexes dynamics were ensembleaveraged for visualization.

\subsection{Statistical analysis}

Data are expressed as mean \pm SD. 20-s epoch means (EM) of the measures time courses were computed. Interand intra-measures EM comparisons in control, BTP, ATP and recovery were performed by ANOVA for repeated measures. Individual linear correlations between ${ }_{\mathrm{P}} \mathrm{LF}$ and ${ }_{\mathrm{CF}} \mathrm{LF}$ dynamics in BTP, ATP and recovery were obtained. Statistical significance was set at $\mathrm{p}<0.05$.

\section{Results}

Linear CIMF, performed by extending both legs, presented: mean maximal force of $33.5 \pm 6.6 \mathrm{~kg}$, endurance time of $150 \pm 19 \mathrm{~s}$ and correlation with time of $0.99 \pm 0.04$, $\mathrm{p}<0.001$ (Fig. 1).

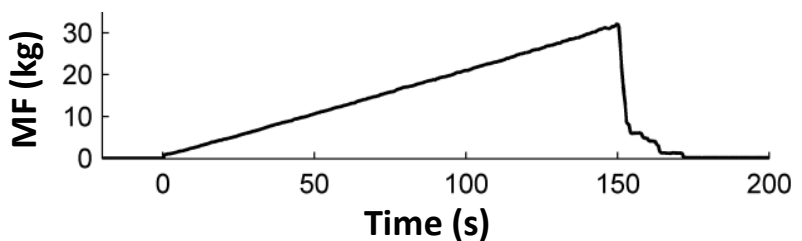

Fig. 1. Ensemble average of linear CIMF vs. time.

Typical examples of time-frequency spectra of RR (Fig.2A) and DP (Fig.2B) displayed the sudden reduction of ${ }_{\mathrm{CF}} \mathrm{LF}$ and the rapid increase of ${ }_{\mathrm{P}} \mathrm{LF}$ in ATP, as well as the inverse behavior in the initial recovery period (IRP).
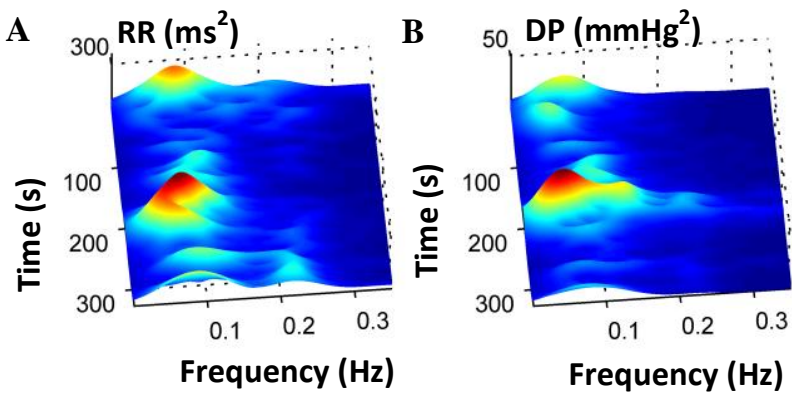

Fig. 2. Representative time-frequency spectra of A) RR and B) DP series during control, CIMF (spanning from 60 to $210 \mathrm{~s}$ ), and recovery.

Ensemble averages of the relations of ${ }_{\mathrm{P}} \mathrm{LF}_{\mathrm{RR}},{ }_{\mathrm{P}} \mathrm{LF}_{\mathrm{SP}}$ and ${ }_{\mathrm{P}} \mathrm{LF}_{\mathrm{DP}}$ dynamics vs. \% $\mathrm{MF}_{\mathrm{MAX}}$ showed similar patterned responses during CIMF: in BTP all ${ }_{\mathrm{P}} \mathrm{LF}$ decreased, ${ }_{\mathrm{P}} \mathrm{LF}_{\mathrm{SP}}$ and ${ }_{\mathrm{PLF}} \mathrm{FP}_{\mathrm{DP}}$ slightly and ${ }_{\mathrm{P}} \mathrm{LF}_{\mathrm{RR}}$ more pronouncedly, followed by a sudden increment in ATP (Fig. 3). Mean thresholds detected by ${ }_{\mathrm{P}} \mathrm{LF}_{\mathrm{SP}},{ }_{\mathrm{P}} \mathrm{LF}_{\mathrm{DP}}$ and ${ }_{\mathrm{P}} \mathrm{LF}_{\mathrm{RR}}$, of $79 \pm 9$, $79 \pm 9,77 \pm 9$ of $\% \mathrm{MF}_{\mathrm{MAX}}$ respectively, were similar.

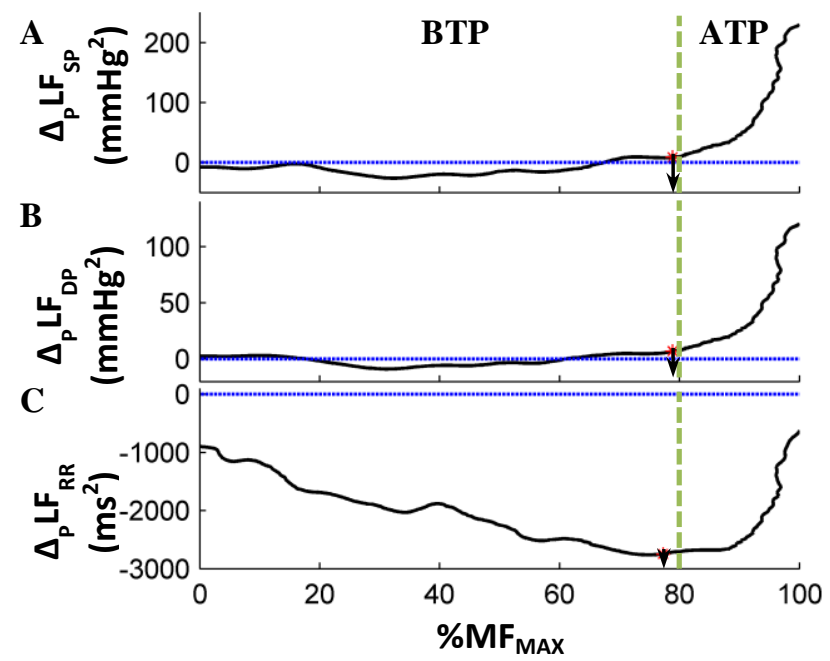

Fig. 3. Ensemble averages of the relations of $\% \mathrm{MF}_{\mathrm{MAX}}$ with: $\left.\mathrm{A})_{\mathrm{P}} \mathrm{LF}_{\mathrm{SP}}, \mathrm{B}\right)_{\mathrm{P}} \mathrm{LF}_{\mathrm{DP}}$ and $\left.\mathrm{C}\right)_{\mathrm{P}} \mathrm{LF}_{\mathrm{RR}}$, expressed as change from baseline during BTP and ATP of CIMF. $\downarrow$ Mark the inflection points in the dynamic corresponding to the mean thresholds in $\% \mathrm{MF}_{\mathrm{MAX}}$. 
Ensemble averages of the ${ }_{\mathrm{CF}} \mathrm{LF}_{\mathrm{SP}}, \mathrm{CF}_{\mathrm{CF}} \mathrm{LF}_{\mathrm{DP}}$ and ${ }_{\mathrm{CF}} \mathrm{LF}_{\mathrm{RR}}$ vs. $\% \mathrm{MF}_{\mathrm{MAX}}$ relations showed similar patterned responses of gradual increment of ${ }_{\mathrm{CF}} \mathrm{LF}_{\mathrm{SP}}$ and ${ }_{\mathrm{CF}} \mathrm{LF}_{\mathrm{DP}}$, more subtle in ${ }_{C F} \mathrm{LF}_{\mathrm{RR}}$, in BTP, and abrupt decrease in ATP (Fig.4), inverse to the pattern presented by ${ }_{\mathrm{p}} \mathrm{LF}$ dynamics, roughly in BTP but notably in ATP (Fig. 3). Mean thresholds detected by ${ }_{\mathrm{CF}} \mathrm{LF}_{\mathrm{SP}}, \mathrm{CF}_{\mathrm{LF}} \mathrm{LF}_{\mathrm{DP}}$ and ${ }_{\mathrm{CF}} \mathrm{LF}_{\mathrm{RR}}$ of $79 \pm 9,80 \pm 9$ and $78 \pm 9 \% \mathrm{MF}_{\mathrm{MAX}}$ respectively, were similar. Thresholds detected by ${ }_{\mathrm{P}} \mathrm{LF}$ and ${ }_{\mathrm{CF}} \mathrm{LF}$ were not different (Fig. 3-4).

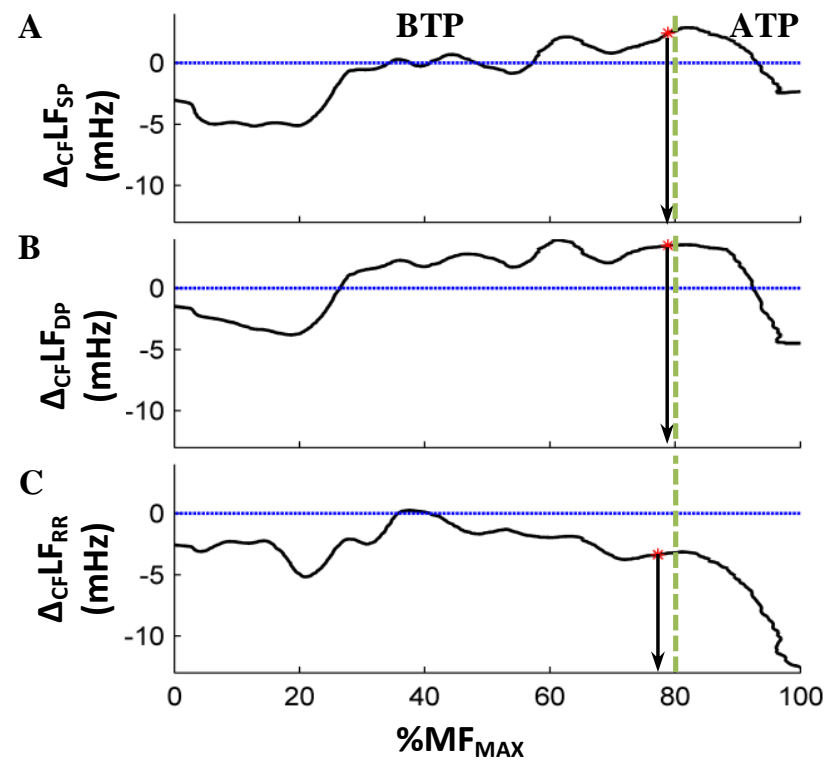

Fig. 4. Ensemble averages of the continuous relations of $\% \mathrm{MF}_{\mathrm{MAX}}$ with: $\left.\left.\mathrm{A}\right)_{\mathrm{CF}} \mathrm{LF}_{\mathrm{SP}}, \quad \mathrm{B}\right)_{\mathrm{CF}} \mathrm{LF}_{\mathrm{DP}}$ and $\mathrm{C}_{\mathrm{CF}} \mathrm{LF}_{\mathrm{RR}}$, expressed as change from baseline during BTP and ATP of CIMF. $\downarrow$ Mark the inflection points in the dynamics corresponding to the mean thresholds in $\% \mathrm{MF}_{\mathrm{MAX}}$.

Ensemble averages of the time courses of ${ }_{\mathrm{CF}} \mathrm{LF}_{\mathrm{SP}}$, ${ }_{C F} L_{D P}$ and ${ }_{C F} L_{F R}$ showed: a fall at the onset of CIMF with respect to control, the smallest corresponding to ${ }_{C F} \mathrm{LF}_{\mathrm{RR}}$; gradual increment in BTP, except for ${ }_{\mathrm{CF}} \mathrm{LF}_{\mathrm{RR}}$, followed by an abrupt fall until the end of CIMF (ATP), that coincides with the start and peak of ${ }_{\mathrm{p}} \mathrm{LF}$ dynamics surge; and a fast increment of the three ${ }_{\mathrm{CF}} \mathrm{LF}$ in the first $40 \mathrm{~s}$ of IRP, where ${ }_{\mathrm{CF}} \mathrm{LF}_{\mathrm{RR}}$ showed the greatest range of change (Fig. 5). EM inter comparison of ${ }_{C F} L_{S P},{ }_{C F} L F_{D P}$ and ${ }_{C F} L F_{R R}$ on each period showed: differences $(p<0.04)$ in control period according to the inequality ${ }_{\mathrm{CF}} \mathrm{LF}_{\mathrm{RR}}$ $(98 \pm 10 \mathrm{mHz})>_{\mathrm{CF}} \mathrm{LF}_{\mathrm{SP}}(91 \pm 12 \mathrm{mHz})>_{\mathrm{CF}} \mathrm{LF}_{\mathrm{DP}}(86 \pm 8 \mathrm{mHz})$ that remained in the initial part of BTP; in the middle and end of BTP, ${ }_{C F} \mathrm{LF}_{\mathrm{SP}}$ was similar to ${ }_{\mathrm{CF}} \mathrm{LF}_{\mathrm{DP}}$ but both were different $(p<0.01)$ to ${ }_{C F} L F_{R R}$; EM of the three ${ }_{C F} L F$ were similar in ATP and IRP, but in the end recovery period (ERP), EM of ${ }_{C F} \mathrm{LF}_{\mathrm{SP}}$ and ${ }_{\mathrm{CF}} \mathrm{LF}_{\mathrm{DP}}$ remained similar and were again different to ${ }_{\mathrm{CF}} \mathrm{LF}_{\mathrm{RR}}(\mathrm{p}<0.01$, Fig. 5). While EM of ${ }_{C F} L F_{R R}$ were different $(p<0.03)$ to control during BTP, ATP and IRP, those of ${ }_{C F} L F_{D P}$ and ${ }_{C F} L_{S P}$ were only different $(\mathrm{p}<0.03)$ in ATP.

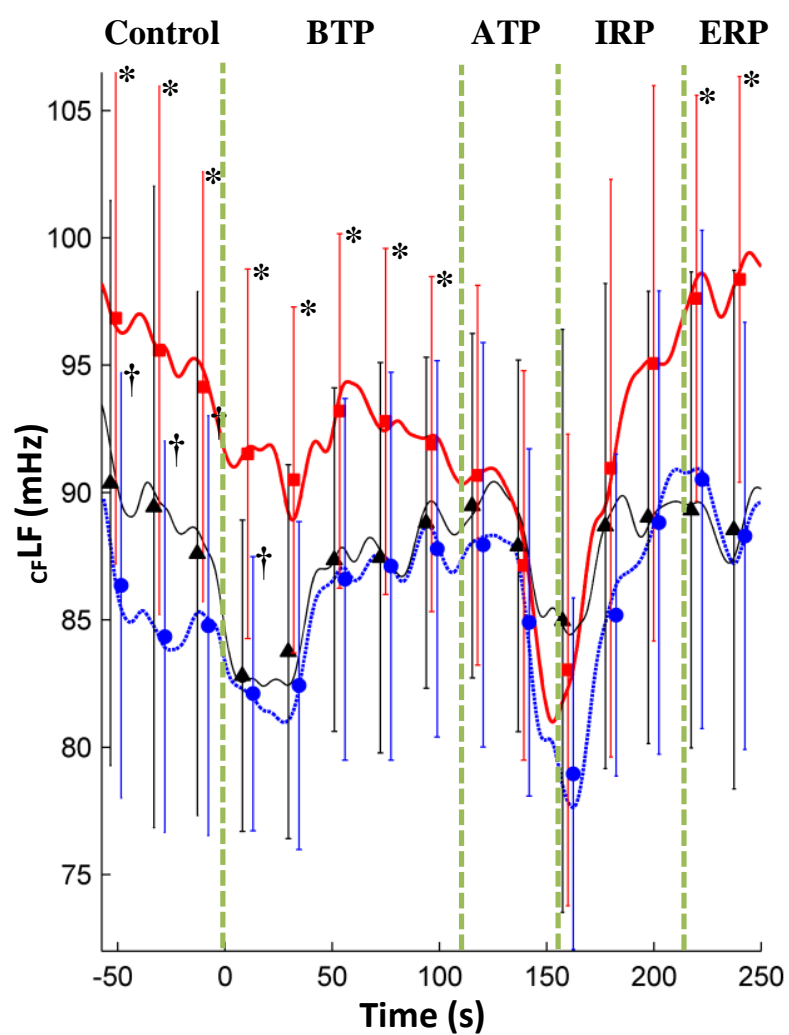

Fig. 5. Ensemble averages and 20-s EM \pm SD of the time courses of ${ }_{\mathrm{CF}} \mathrm{LF}_{\mathrm{SP}}$ (black thin solid line), ${ }_{\mathrm{CF}} \mathrm{LF}_{\mathrm{DP}}$ (blue dotted line), ${ }_{C F} \mathrm{LF}_{\mathrm{RR}}$ (red thick solid line) during control, BTP, ATP, IRP and ERP. ${ }^{*} \mathrm{p}<0.04{ }_{\mathrm{CF}} \mathrm{LF}_{\mathrm{RR}}$ vs. ${ }_{\mathrm{CF}} \mathrm{LF}_{\mathrm{SP}} . \dagger \mathrm{p}<0.01 \mathrm{CF}_{\mathrm{CF}} \mathrm{LF}_{\mathrm{DP}}$ Vs. $\mathrm{CF}_{\mathrm{LF}} \mathrm{LF}_{\mathrm{SP}}$.

Mean ${ }_{\mathrm{CF}} \mathrm{LF}-\mathrm{p} \mathrm{LF}$ correlations, shown in Table 1, were: significant $(\mathrm{p}<0.01)$, negative and different between periods, according to the inequality ATP $>$ IRP $>$ BTP.

Table 1. Mean \pm SD of correlations between ${ }_{\mathrm{CF}} \mathrm{LF}$ and ${ }_{\mathrm{P}} \mathrm{LF}$ of the three variables in BTP, ATP and IRP. N=31.

\begin{tabular}{|c|c|c|c|}
\hline & ${ }_{C F} \mathbf{L F}_{\mathrm{DP}-\mathrm{P}} \mathbf{L F}_{\mathrm{DP}}$ & ${ }_{\mathrm{CF}} \mathbf{L F}_{\mathrm{SP}-\mathrm{P}} \mathbf{L F}_{\mathrm{SP}}$ & ${ }_{C F} L_{R_{R R}-\mathrm{P}} \mathbf{L F}_{\mathrm{RR}}$ \\
\hline BTP & $-0.17 \pm 0.39^{*}$ & $-0.14 \pm 0.35^{*}$ & $-0.15 \pm 0.41^{*}$ \\
\hline ATP & $-0.83 \pm 0.14 \dagger$ & $-0.83 \pm 0.24 \dagger$ & $-0.75 \pm 0.36 \dagger$ \\
\hline IRP & $-0.67 \pm 0.20$ & $-0.64 \pm 0.30$ & $-0.54 \pm 0.38$ \\
\hline
\end{tabular}

\section{Discussion}

The dynamics of sympathetic activity changes are assessed by the low frequency components of CVV in the main dimensions of spectral analysis, power and central frequency over time, as supported by the finding that the instantaneous time courses of ${ }_{\mathrm{CF}} \mathrm{LF}_{\mathrm{SP}}, \mathrm{CF}_{\mathrm{LF}} \mathrm{LF}_{\mathrm{DP}}$ and ${ }_{\mathrm{CF}} \mathrm{LF}_{\mathrm{RR}}$ show: 1) similar patterned responses of gradual increment in BTP and abrupt decrease in ATP followed by a rapid increase in IRP (Fig.5), roughly inverse to the pattern presented by ${ }_{\mathrm{P}} \mathrm{LF}$ dynamics in BTP but noticeably so in 
ATP and IRP (Fig. 3); 2) inter-measures differences in control and BTP according to the inequality: ${ }_{\mathrm{CF}} \mathrm{LF}_{\mathrm{RR}}>_{\mathrm{CF}} \mathrm{LF}_{\mathrm{SP}}>_{\mathrm{CF}} \mathrm{LF}_{\mathrm{DP}}$, that disappear in ATP and IRP but return to control values in ERP (Fig. 5); and 3) negative correlations with their corresponding ${ }_{\mathrm{P}} \mathrm{LF}$, greater in ATP and IRP than BTP (Table 1).

The combination of linear CIMF, continuous response measurement and time-frequency analysis allows assessing the degree of stimulus-response proportionality, providing greater robustness to the evidence. This situation contrasts with the leftward shift of ${ }_{\mathrm{CF}} \mathrm{LF}_{\mathrm{RR}}$ documented by a single mean value in other studies [4,5].

A possible explanation for the differences found in control period between the magnitudes of the three ${ }_{\mathrm{CF}} \mathrm{LF}$ dynamics is that the sympathetic autonomic nuclei that innervate the heart modulate $\mathrm{RR}$ series at a greater frequency (centered around $98 \mathrm{mHz}$ ) than the ones that innervate the vessels, modulating DP series (about 86 $\mathrm{mHz}$ ). Thus, cardiac and vasomotor sympathetic branches not only show a different anatomic distribution but operate at different modulating frequencies. The intermediate frequency of SP series would result from the influence of both modulatory branches, with some prevalence of the vasomotor one. During BTP, with the reduction of vasomotor sympathetic activity the differences between ${ }_{\mathrm{CF}} \mathrm{LF}_{\mathrm{SP}}$ and ${ }_{\mathrm{CF}} \mathrm{LF}_{\mathrm{DP}}$ disappear, but they remain different from ${ }_{C F} L F_{R R}$, fact that further supports the functional differences between sympathetic branches. In ATP, the abrupt activity increase of both sympathetic branches makes the three ${ }_{\mathrm{CF}} \mathrm{LF}$ to become similar, effect that remains until IRP (Fig. 5). In ERP, ${ }_{C F} L_{R R}$ is again greater than ${ }_{C F} L_{S P}$ and ${ }_{C F} L F_{D P}$. Another possible contributing effect to the ${ }_{\mathrm{CF}} \mathrm{LF}$ change is the resonance of the feedback loop of AP that has been documented by the autoregressive modeling of the leftward shift of ${ }_{\mathrm{CF}} \mathrm{LF}_{\mathrm{RR}}$ under tilt condition [6].

The negative correlations found between ${ }_{\mathrm{CF}} \mathrm{LF}$ and ${ }_{\mathrm{P}} \mathrm{LF}$ (Table 1) show another case of the inverse relations between the amplitude and frequency of the same signal that is added to those already known to physiologists, such as the ones of electroencephalographic rhythms and respiratory sinus arrhythmia, with the peculiarity that the leftward shift of ${ }_{\mathrm{CF}} \mathrm{LF}$ with growing ${ }_{\mathrm{P}} \mathrm{LF}$ indicates sympathoexcitation, as it occurred in ATP, and the rightward ${ }_{\mathrm{CF}} \mathrm{LF}$ shift with reduced ${ }_{\mathrm{P}} \mathrm{LF}$ marks sympathoinhibition, as in BTP and recovery. The sympathoexcitatory effect provoked by CIMF in ATP, marked by the leftward shift of ${ }_{\mathrm{CF}} \mathrm{LF}_{\mathrm{RR}}$, agrees with the reports of previous studies in other sympathetic maneuvers [4-6]. Additionally, ${ }_{C F} L F_{R R}$ has been proposed as a good feature to discriminate autonomic impairment in diabetic patients from normals [7] and newborn seizures from non-seizures [8].

To the best of our knowledge, this is the first study to report that ${ }_{\mathrm{CF}} \mathrm{LF}$ show significant correlations with ${ }_{\mathrm{P}} \mathrm{LF}$ that improve in ATP, correctly indicate the threshold of metaboreflex triggering and present different baselines that are modified by CIMF, supporting their possible use as sympathetic activity measures, with some specificity: ${ }_{\mathrm{CF}} \mathrm{LF}_{\mathrm{RR}}$ marks cardiac sympathetic activity and ${ }_{\mathrm{CF}} \mathrm{LF}_{\mathrm{DP}}$ the vasomotor one, although further studies are required to confirm these notions.

In conclusion, the significant and characteristic changes elicited by CIMF in ${ }_{\mathrm{CF}} \mathrm{LF}_{\mathrm{SP}}, \mathrm{CF}_{\mathrm{CF}} \mathrm{LF}_{\mathrm{DP}}$ and ${ }_{\mathrm{CF}} \mathrm{LF}_{\mathrm{RR}}$, correctly indicate, but inversely, the known responses of reduction and abrupt increment of sympathetic activity before and after metaboreflex triggering. ${ }_{\mathrm{CF}} \mathrm{LF}_{-\mathrm{P}} \mathrm{LF}$ association grows with sympathoactivation, as shown by the greater correlations found in ATP. The different ${ }_{\mathrm{CF}} \mathrm{LF}$ levels and their changes found suggest that the cardiac modulatory sympathetic effect presents greater operating frequency than the vasomotor one. These findings suggest that ${ }_{\mathrm{CF}} \mathrm{LF}_{\mathrm{SP}},{ }_{\mathrm{CF}} \mathrm{LF}_{\mathrm{DP}}$ and ${ }_{\mathrm{CF}} \mathrm{LF}_{\mathrm{RR}}$ can be trustable vasomotor or cardiac sympathetic outflow indicators that complement and strengthen the performance of the usual autonomic activity spectral measures.

\section{References}

[1] Task Force of the European Society of Cardiology and the North American Society of Pacing and Electrophysiology. "Heart rate variability standards of measurement, physiological interpretation, and clinical use". Eur Heart $J$ 1996;17: 354-381.

[2] Parati G, Mancia G, Di Rienzo M, Castiglioni P. "Point: cardiovascular variability is/is not an index of autonomic control of circulation". J Appl Physiol 2006;101:676-8.

[3] Guillén-Mandujano A, Carrasco-Sosa S. "Effects of two types of linearly increased isometric exercise on instantaneous baroreflex and respiratory sinus arrhythmia sensitivities computed by alpha index". Comput Cardiol 2018;45. DOI: 10.22489/CinC.2018.025

[4] Weise F, Heydenreich F. "Effects of modified respiratory rhythm on heart rate variability during active orthostatic load". Biomed Biochim Acta 1989;48:549-56.

[5] Kamath M, Fallen E, McKelvie R. "Effects of steady state exercise on the power spectrum of heart rate variability". Med Sci Sports Exerc 1991;23:428-34.

[6] Raymond B, Mazumdar J, Nandagopal D. "Modelling the shift of the low frequency component of heart rate variability". Comput Cardiol 1997;24:407-10.

[7] Lanting P, Faes T, Heimans J, ten Voorde B, Nauta J, Rompelman O. "Spectral analysis of spontaneous heart rate variation in diabetic patients". Diabet Med 1990;7:705-10.

[8] Malarvili M, Mesbah M, Boashash B. "Time-frequency analysis of heart rate variability for neonatal seizure detection". Australas Phys Eng Sci Med 2006;29:67-72.

Address for correspondence.

Alejandra Guillén-Mandujano

Depto. Ciencias de la Salud, T-172. UAM-I, CDMX, México. ale.guillen.mandujano@gmail.com 